\title{
ANÁLISE FINANCEIRA E ECONÔMICA DO BALANÇO PATRIMONIAL E DA DEMONSTRAÇÃO DO RESULTADO DO EXERCÍCIO COMO SUPORTE NAS DECISÕES DO DEPARTAMENTO FINANCEIRO
}

\section{ARTIGO ORIGINAL}

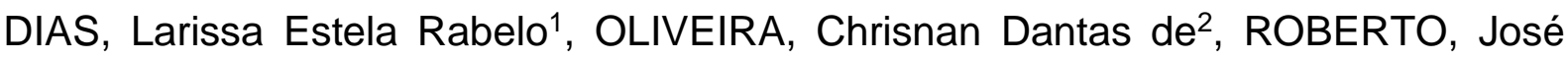
Carlos Alves $^{3}$, SERRA, Meg Rocha da Cunha ${ }^{4}$, LOPES, Nelânia Ferreira ${ }^{5}$

DIAS, Larissa Estela Rabelo. Et al. Análise financeira e econômica do balanço patrimonial e da demonstração do resultado do exercício como suporte nas decisões do departamento financeiro. Revista Científica Multidisciplinar Núcleo do Conhecimento. Ano. 06, Ed. 11, Vol. 11, pp. 51-79. Novembro 2021. ISSN: 24480959, Link de acesso:

https://www.nucleodoconhecimento.com.br/contabilidade/demonstracao-doresultado,

DOI: 10.32749/nucleodoconhecimento.com.br/contabilidade/demonstracao-do-resultado

\section{RESUMO}

O proposito dessa pesquisa bibliográfica é facilitar o dia a dia do usuário da contabilidade, onde, por meio de análises, pode-se aumentar a eficiência na tomada de decisões a curto, médio e em longo prazo no departamento financeiro das organizações. O problema de pesquisa abordado é: Como as análises financeiras e econômicas de balanço patrimonial e da demonstração do resultado do exercício

\footnotetext{
${ }^{1}$ Graduando do curso de Ciências Contábeis.

${ }^{2}$ Graduanda do curso de Ciências Contábeis.

${ }^{3}$ Orientador. Mestrado profissional em Engenharia de Produção. Especialização em Gestão em Logística empresarial. Graduação em Administração com ênfase em Marketing.

${ }^{4}$ Orientadora. Mestra em Engenharia de Processos Industriais pela UFPA, especialista em Controladoria e Auditoria Contábil pelo Ciesa, Graduada em Ciências Contábeis pelo Centro Universitário do Norte. Graduada em Ciências Econômicas pelo Centro Universitário do Norte.

${ }^{5}$ Especialista em Auditoria Contábil, Financeira e Tributária e Graduada em Ciências Contábeis.
} 
podem contribuir com a tomada melhores decisões e na obtenção de melhor desempenho no departamento financeiro? Objetivo geral do estudo é destacar a importância das análises financeira e econômica de balanço patrimonial e da demonstração do resultado do exercício para o suporte nas decisões do departamento financeiro. O estudo tem natureza básica, apresenta-se como pesquisa explicativa e bibliográfica. Os resultados verificados no estudo fundamentam como a demonstração do cálculo e análises econômicas de forma técnica fornecem informações que aperfeiçoam o processo de tomada de decisão, fornecendo informações que se tornam dados importantes para mensurar a saúde financeira da empresa a partir das demonstrações, possibilitando organizar melhores práticas para gerar lucro e, consequentemente, aumentar a eficiência de seus indicadores operacionais e financeiros. Conclui-se que as técnicas abordadas neste estudo auxiliam no desenvolvimento do sucesso de uma empresa e o contador é um profissional essencial para orientar a alavancagem desta no sentido de obter liquidez, pois fazem, diariamente, investimentos e projeções em longo prazo, com vistas a aumentarem a lucratividade, utilizando os índices para melhoria contínua e partindo do planejamento dos recursos para realizarem melhores investimentos.

Palavras-chave: Demonstrações Contábeis, Análise financeira, Análise econômica, tomada de decisões, Índices financeiros.

\section{INTRODUÇÃO}

Este artigo trata-se de um estudo bibliográfico que tem como objetivo apresentar a melhor forma para que as análises financeira e econômica de balanço patrimonial e da demonstração do resultado do exercício possam refletir em uma melhor forma de oferecer suporte às decisões do departamento financeiro, o que trará melhores resultados. Menciona-se, portanto, que as análises das demonstrações contábeis exercem uma importância fundamental na etapa relacionada à tomada de decisões, de maneira que oferecem indicadores com as perspectivas econômicas e financeiras da empresa. Isto proporciona uma gestão mais segura dos recursos que a empresa 
disponibiliza, tornando mais certeiras as decisões, bem como propicia-se resultados melhores para a entidade.

Para definirmos a questão-problema da pesquisa, fizemos o seguinte questionamento: qual tipo de análise devemos fazer para sanar tais lacunas, de modo que nos deparamos com a seguinte questão: Como as análises financeiras e econômicas de balanço patrimonial e da demonstração do resultado do exercício podem contribuir com a tomada melhores decisões e na obtenção de melhor desempenho no departamento financeiro? Objetivo geral do estudo é destacar a importância das análises financeira e econômica de balanço patrimonial e da demonstração do resultado do exercício para o suporte nas decisões do departamento financeiro.

O estudo tem natureza básica e, quanto aos fins, escolhemos a pesquisa explicativa. Referente aos meios, utilizamos os meios bibliográficos de pesquisa. O presente artigo busca entender, a partir da análise dos aspectos relacionados, como o resultado facilita as decisões do departamento financeiro, demonstrando como as análises financeira e econômica de balanço patrimonial e da demonstração do resultado do exercício podem contribuir para o planejamento do departamento financeiro.

Busca-se, também, explicar como o departamento financeiro pode influenciar positivamente nos resultados da contabilidade por meio de uma boa organização. Para tanto, ao longo do artigo, apresenta-se as sete principais técnicas de análise econômico-financeira que adaptamos para o contexto de nossa pesquisa, contandose, também, com alguns exemplos relacionados ao cenário.

Com isto, buscamos contribuir com as empresas que almejam o alcance dos melhores resultados, principalmente com aquelas que têm buscado se estruturar de maneira mais profissional, estando mais preparadas para desempenharem os seus procedimentos, assim como buscamos alertar aos profissionais da área que a base 
da contabilidade ainda é o mais importante e é o processo de desperta os melhores resultados, se soubermos utilizá-la.

\section{FUNDAMENTAÇÃO TEÓRICA}

Zanella (2013), afirma que a fundamentação teórica ou referencial teórico é um dos processos da pesquisa científica que incide na revisão de textos, artigos, livros e todos os materiais relacionados à área ou ao assunto estudado. Então, ela é a etapa do trabalho que auxilia na coleta e análise das informações e apresenta os conceitos, modelos e teorias que sustentarão a argumentação do pesquisador. Neste sentido, deve-se buscar fontes autênticas e que ofereçam dados de qualidade para a pesquisa.

\subsection{CONTABILIDADE}

Para Padoveze (2014), a contabilidade é o sistema de informação que controla o patrimônio da entidade por meio da arrecadação, armazenamento e processamento das informações que são consequências dos fatos que mudam essa massa patrimonial. Conforme Martins; Miranda e Diniz (2012), pode-se compreender que a contabilidade é o modelo de representação da situação econômica e financeira de uma entidade; segundo, a existência de grande diversidade de usuários da informação contábil. Ou seja, a contabilidade é o material de apoio para avaliação de decisões de seus usuários, que podem ser o dono do patrimônio ou os acionistas, profissionais da contabilidade, governo, bancos, financiadoras e clientes. Martins; Diniz e Miranda (2012) afirmam que a contabilidade é um modelo que procura representar o que tem ocorrido com a empresa, mas este modelo, como aponta a regra, apresenta a realidade de uma forma mais simples, pois representa as pessoas que habitam em um meio, porém, trata-se, sempre, de uma representação parcial da realidade, nunca será ela por inteiro. Capta-se fragmentos. 
Sempre apontará para algo para a realidade de uma maneira simplista, o que faz com que sejam reduzidas as informações vitais ao entendimento completo daquilo que acontece em um momento específico, em um contexto específico.

\subsubsection{USUÁRIO DA CONTABILIDADE}

Conforme Padoveze (2014), os usuários da contabilidade são os administradores, proprietários, acionistas ou investidores, contadores e auditores internos e outros funcionários. Entre os usuários das demonstrações contábeis, incluem-se investidores atuais e potenciais, funcionários, credores, fornecedores e outros credores comerciais, clientes, governo e o público. Esses usuários, embora possuam necessidade de acesso às informações comuns, também necessitam de informações específicas. O usuário da contabilidade tem como sua responsabilidade chegar às conclusões sobre relatórios econômicos e financeiros, dando suporte aos tomadores de decisões. Também é ele que registra todas as operações, organiza e trata, até chegar ao relatório final, que é representado pelas demonstrações financeiras.

O objetivo da análise depende do usuário ao qual a demanda se volta. A tomada de decisão necessita de informações específicas. Os investidores, por exemplo, interessam-se pelos resultados, riscos de investimento a curto e longo prazo, retorno de capital e pagamento de dividendos. Os credores são aqueles que demonstram interesse por empréstimos, porém, os fornecedores também têm esse interesse, caso a empresa tenha a capacidade de cumprir com suas obrigações nas datas estabelecidas. Já os sindicatos e empregados estão interessados na estabilidade e lucratividade, pagamentos de salários em dia, demais benefícios e oportunidades de emprego internamente. Já os clientes se interessam pelo fornecimento dos pedidos e matéria prima e os fornecedores pelos créditos e a sua disponibilidade. Já o governo necessita de informações sobre as atividades empresariais para estabelecer as políticas fiscais, tributação correta para cada tipo de empresa e para melhor destinação de recursos. 


\subsection{DEMONSTRAÇÕES FINANCEIRAS}

De acordo com Martins; Miranda e Diniz (2012), o Balanço Patrimonial e a Demonstração do Resultado do Exercício dizem respeito às demonstrações financeiras tradicionais. Ao serem elaboradas e publicadas por uma empresa não têm, isoladamente, grandes chances de apontarem suas forças e fraquezas, pois trazem informações financeiras em condições absolutas que não transmite tudo que se faz necessário para o analista. Logo, as demonstrações financeiras dizem respeito ao balanço patrimonial de demonstração do resultado do exercício, sob a visão de um profissional da área financeira que busca interpretá-las com olhos focados no resultado financeiro e na programação futura. Deve empregar as técnicas corretas para esta análise.

Martins; Miranda e Diniz (2012) citam, ainda, que entendem que as habilidades do analista devem compreender a) conhecimento inerente ao campo do negócio em que atua, isto é, a atividade, o setor, as pessoas envolvidas, os julgamentos utilizados etc. interferem na produção de tal conhecimento; b) conhecimento sobre o modelo contábil e as particularidades para cada tipo de empresa especificamente.

\subsubsection{BALANÇO PATRIMONIAL (BP)}

Padoveze (2014) explica que se denomina como Balanço Patrimonial o conjunto de ativos e passivos. Este nome advém da ideia literal de equilíbrio entre o ativo e o passivo. O Balanço Patrimonial é a demonstração contábil que tem como finalidade demonstrar a posição contábil, econômica e financeira da empresa em uma determinada data, ou seja, representação estática do patrimônio. No Balanço Patrimonial, as contas precisarão ser qualificadas de acordo com os elementos do patrimônio. É preciso que tais contas registrem e sejam reunidas de modo a promoverem a ciência e a apreciação quanto à situação financeira da empresa. $\mathrm{O}$ Balanço Patrimonial é constituído pelo Patrimônio Líquido, Passivo e pelo Ativo, conforme a Lei № 6.404/76 (Arts. 176 a 182 e Art. 187) e NBC T.3. 
O Ativo abrange aplicações de recursos controlados pela entidade, sendo elas capazes de gerar diversos benefícios econômicos futuros, originados de eventos ocorridos, assim como os bens e os direitos que a entidade possui. O Passivo abrange as origens de recursos expostos pelas obrigações para com terceiros, tais como fornecedores e outros, resultados de eventos que ocorreram que irão precisar de ativos para a sua cobertura. O Patrimônio Líquido abrange os recursos que são de propriedade da entidade e seu valor é a diferença positiva entre o valor do Passivo e o valor do Ativo.

\subsubsection{ATIVO}

De acordo com o que Assaf Neto (2012) prega, ativos são recursos resultados de eventos passados que são controlados pela entidade dos quais espera-se que resultem em benefícios econômicos futuros para a entidade. Neles, as contas devem ser exibidas em ordem decrescente, sendo que esta aponta o grau de liquidez dos itens ali registrados.

\subsubsection{ATIVO CIRCULANTE}

Abrange valores praticados no exercício social subsequente. Neste caso, por exemplo, uma empresa a qual o exercício social se encerra em 31 de dezembro, ao realizar o encerramento do exercício no dia 31 de dezembro de um ano, deverá considerar no Ativo Circulante todos os valores realizados até 31 de dezembro do ano seguinte (neste caso, 2021). Nas entidades em que o ciclo operacional tiver duração maior que 1 ano, que é o exercício social, a classificação obedecerá a um novo critério que será o tempo deste ciclo que a empresa pratica. Porém, raramente é usado dessa forma. Adotamos o padrão de 1 ano para classificação das contas como circulante, se forem realizáveis ou exigíveis neste período de tempo. 


\subsubsection{ATIVO NÃO CIRCULANTE}

Estão neste grupo todos os bens de continuação duradoura destinados ao funcionamento habitual da sociedade e do seu empreendimento, assim como os direitos exercidos com esse objetivo.

O Ativo Não Circulante será composto dos seguintes subgrupos:

- Ativo Realizável a Longo Prazo;

- Investimentos;

- Imobilizado;

- Intangível

\subsubsection{ATIVO REALIZÁVEL A LONGO PRAZO}

Aqui se classificam as mesmas contas de natureza das do Ativo Circulante, só que, pela lógica, são realizáveis após o ciclo operacional utilizado como critério no circulante e, conforme é feita a reclassificação lá, automaticamente, faz-se a do Não Circulante, ou seja, tem-se a sua efetivação certa ou provável após o fim do exercício seguinte, o que, normalmente, quer dizer realização num período superior a um ano a partir do próprio balanço. As despesas encaixáveis após o exercício seguinte ainda são classificadas no Ativo Realizável a Longo Prazo. Os direitos não resultados de adiantamentos, vendas e ou empréstimos a sociedades coligadas ou controladas, acionistas, diretores ou participantes no lucro da empresa, que não instituírem negócios comuns na exploração do elemento da empresa, serão considerados no Ativo Realizável a Longo Prazo.

\subsubsection{INVESTIMENTOS}

Os investimentos dizem respeito a um subgrupo do Ativo Não Circulante. Nele, devem ser consideradas as participações societárias constantes, desde que atingidas as importâncias aplicadas na obtenção de ações e outros títulos de participação societária, com intuito de mantê-las em estilo permanente, seja para se

RC: 101796

Disponível em:

https://www.nucleodoconhecimento.com.br/contabilidade/demonstracao-do-resultado 
alcançar o comando societário, seja por focos econômicos e, dentre eles, investigase a fonte durável de renda.

\subsubsection{IMOBILIZADO}

O Ativo Imobilizado é composto pelo grupo de bens e direitos essenciais à manutenção das atividades da empresa, diferenciados por apresentarem-se no formato tangível (ex: máquinas, edifícios etc.). O Imobilizado envolve, também, os custos das reformas, benfeitorias e reparos realizados em bens locados ou arrendados.

\subsubsection{INTANGÍVEL}

Os Ativos Intangíveis envolvem o montante de bens incorpóreos destinados à sustentação e manutenção da entidade ou exercidos com esse alvo, inclusive o fundo de comércio obtido. Trata-se de uma subdivisão do Ativo Imobilizado, que, a partir do momento em que a Lei № $11.638 / 2007$ passou a vigorar, ou seja, a partir de 01 de janeiro de 2008, passou-se a contar somente os bens corpóreos de uso permanente.

São exemplos de intangíveis as marcas e patentes, softwares, os direitos de usufruir de serviços públicos mediante concessão ou permissão do Poder Público e o fundo de comércio obtido.

\subsubsection{PASSIVO}

Ainda de acordo com Alexandre (2010), Passivos são as obrigações existentes da entidade, oriundas de eventos já acontecidos, nos quais a liquidação depende da saída de recursos capazes de gerar benefícios econômicos. De forma analógica ao Ativo, aqui, as contas devem ser exibidas em formato decrescente quanto ao grau de exigibilidade. 


\subsubsection{PASSIVO CIRCULANTE}

Neste grupo devem contar as escriturações das obrigações da entidade, inclusive financiamentos para adquirir direitos do Ativo Não-circulante, quando são liquidadas no exercício consequente. Porém, no caso de o ciclo operacional da entidade ter permanência maior que a do exercício social, a compreensão terá por base o prazo desse ciclo.

\subsubsection{PATRIMÔNIO LÍQUIDO}

É a diferença entre o valor dos Passivos e dos Ativos. É formado por Capital Social, Reservas de Capital, Ajustes de Avaliação Patrimonial, Reservas de Lucros, Ações em Tesouraria e Prejuízos Acumulados.

\subsubsection{NOTAS EXPLICATIVAS AO BALANÇO PATRIMONIAL}

Assaf Neto (2010) também aponta, em seu estudo, que as notas explicativas são parte integrante das demonstrações contábeis pelo fato de os relatórios não trazerem o total das informações necessárias para os interessados em visualizar a situação financeira, patrimonial e econômica da empresa. As notas explicativas nascem como um complemento importante ao balanço. Elas têm o objetivo de explicar dados inseridos no Balanço Patrimonial, como o próprio nome diz, visto que algumas das informações podem parecer fora do normal ou incorretas, precisando de justificativas. Elas devem ser estruturadas objetivando proporcionar dados detalhados necessários ao entendimento dos fatos registrados nas demonstrações contábeis obrigatórias.

\subsubsection{DEMONSTRAÇÃO DO RESULTADO DO EXERCÍCIO (DRE)}

Assaf Neto (2010) nos mostra, também, em sua pesquisa, que a Demonstração do Resultado do Exercício (DRE) é um relatório contábil que exibe a abreviação da posição financeira da empresa em um apurado período, conforme o regime de 
competência, com base nas modificações fomentadas pela lei № 11.638/07, eliminando-se as despesa e receitas não operacionais. A Lei correlaciona o que foi delineado no orçamento com as receitas e despesas, divulgando o resultado líquido do negócio, ou seja, aponta-se se o que a empresa obteve como resultado foi lucro ou prejuízo operacional. Com os impostos, custos, receitas, despesas detalhadas, o empreendedor tem uma noção acerca da situação financeira da empresa e, dessa forma, consegue tomar decisões mais eficazes.

A DRE pode ser mensal, bimestral, semestral ou anual, cabendo ao negócio, estar sujeito ao período a ser analisado, o que implica o exame constante do desempenho pela gestão. Seu formato anual é imperativo para algumas empresas, mas todas podem emitir relatório para se beneficiarem quanto ao entendimento do desempenho financeiro do negócio e suas implicações econômicas. A Demonstração do Resultado do Exercício deve ter em sua estrutura, segundo a Lei № $11.638 / 07$ :

Receita Bruta

(-) Deduções e abatimentos

(=) Receita Líquida

(-) CPV (Custo de produtos vendidos) ou CMV (Custos de mercadorias vendidas)

(=) Lucro Bruto

(-) Despesas com Vendas

(-) Despesas Administrativas

(-) Despesas Financeiras

(=) Resultado Antes IRPJ CSLL 
(-) Provisões IRPJ E CSLL

(=) Resultado Líquido.

\subsection{ANÁLISE FINANCEIRA}

Segundo Assaf Neto (2012), para que a análise da estrutura financeira de uma empresa seja realizada, é necessário envolver o estudo de um conjunto de indicadores operacionais que irão espelhar todas as decisões tomadas ligadas ao capital de giro e seu equilíbrio financeiro, focando na formulação analítica de alavancagem financeira. Portanto, a análise financeira das demonstrações contábeis é o esforço realizado para que a empresa busque o seu equilíbrio financeiro de maneira que possa chegar aos melhores resultados.

\subsection{ANÁLISE ECONÔMICA}

Ainda para Assaf Neto (2012), a análise econômica foca em mensurar o valor econômico agregado por meio da elaboração analítica da avaliação do desempenho econômico criada a partir do retorno de investimentos e retorno sobre o ativo, sendo que o objetivo econômico de toda empresa é maximizar o seu valor mensurado no mercado, atentando-se ao indicador do "valor econômico adicionado". Assim, demonstra-se as estratégias financeiras aplicadas que agregam este valor de forma a estruturar sua viabilidade econômica e a continuidade do empreendimento. Com isso, a análise econômica das demonstrações contábeis necessita de uma boa análise financeira, pois uma é consequência da outra, se na alavancagem financeira forem aplicados métodos eficazes, isso impactará diretamente aqui, e nos dirá se a estratégia financeira está funcionando ou não.

\subsection{PRINCIPAIS TÉCNICAS DE ANÁLISE ECONÔMICO-FINANCEIRA}

Para Assaf Neto e Silva (2012), o raciocínio básico da análise de balanço desenvolve-se por meio de técnicas oriundas de diferentes áreas do saber, como da contabilidade, matemática e, principalmente, estatística. Essas técnicas permitem 
um uso bastante abrangente e passam continuamente por um processo comum de aprimoramento e refinamento. Os métodos de avaliação aplicados pelas empresas baseados na experiência, por sua vez, trazem evidências científicas ao longo do tempo, atestando suas legitimidades. Assaf Neto e Silva (2012) aponta que a análise das demonstrações contábeis assume uma importância fundamental no processo decisório, constituindo-se um relevante instrumento de avaliação de desempenho, oferecendo indicadores a serem aplicados às perspectivas econômicas e financeiras da empresa. Um dos objetivos da contabilidade é criar condições para cada usuário que utiliza dos seus dados e relatórios para avaliação da empresa, portanto, contribuem com a tomada de decisões no departamento financeiro.

É uma estrutura conceitual básica, segundo Martins; Diniz e Miranda (2012). Foi desenvolvida de modo a ser aplicável a uma gama de modelos contábeis e abrange conceitos sobre os capitais e sua manutenção. De forma prática e clara, apresenta orientações e interpretações dentro das normas contábeis, promovendo a padronização das regularidades durante a demonstração de resultados gerenciais.

\subsubsection{ANÁLISE VERTICAL}

Para Assaf Neto (2012), o estudo vertical das demonstrações contábeis permite conhecer a estrutura financeira e econômica da empresa, ou seja, a participação relativa de cada elemento patrimonial e os resultados. Durante a análise vertical é possível, também, descobrir as causas primárias, caso haja erro de estrutura dentro de um conjunto de contas no Balanço Patrimonial.

Fórmula para calcular análise vertical:

$$
\mathrm{AV}=\frac{\text { Afivo Circulante }+ \text { Realizável longo Prazo }}{\text { Passivo Circulante }+ \text { Exiglvel Longo Prazo }} \times 100
$$


Tabela 01 - Exemplo de Cálculo Análise Vertical

\begin{tabular}{|c|c|c|c|c|c|c|}
\hline Exercício & $\begin{array}{l}\text { 31.12.2019 } \\
\text { (R\$ mil) }\end{array}$ & $\begin{array}{l}\text { AV } \\
\text { (№ } \\
\text { Índice) }\end{array}$ & $\begin{array}{l}31.12 .2020 \\
\text { (R\$ mil) }\end{array}$ & $\begin{array}{l}\text { AV } \\
\text { (№ } \\
\text { Índice) }\end{array}$ & $\begin{array}{l}31.12 .2021 \\
\text { (R\$ mil) }\end{array}$ & $\begin{array}{l}\text { AV } \\
\text { (№ } \\
\text { Índice) }\end{array}$ \\
\hline $\begin{array}{l}\text { Ativo } \\
\text { Circulante }\end{array}$ & $3.909,00$ & $54,66 \%$ & $4.200,00$ & $51,36 \%$ & $4.210,00$ & $44,72 \%$ \\
\hline $\begin{array}{l}\text { Realizável a } \\
\text { LP }\end{array}$ & 567,00 & $7,93 \%$ & 678,00 & $8,29 \%$ & 995,00 & $10,57 \%$ \\
\hline Permanente & $2.675,00$ & $37,41 \%$ & $3.300,00$ & $40,35 \%$ & 4210 & $44,72 \%$ \\
\hline $\begin{array}{l}\text { Ativo/Passivo } \\
\text { Total }\end{array}$ & $7.151,00$ & $100 \%$ & $8.178,00$ & $100 \%$ & $9.415,00$ & $100 \%$ \\
\hline $\begin{array}{l}\text { Passivo } \\
\text { Circulante }\end{array}$ & $2.980,00$ & $41,67 \%$ & $3.189,00$ & $38,99 \%$ & $4.100,00$ & $43,55 \%$ \\
\hline $\begin{array}{l}\text { Exigível a } \\
\text { LP }\end{array}$ & $1.390,00$ & $19,44 \%$ & $1.569,00$ & $19,19 \%$ & $1.765,00$ & $18,75 \%$ \\
\hline $\begin{array}{l}\text { Patrimônio } \\
\text { Líquido }\end{array}$ & 2781 & $38,89 \%$ & $3.420,00$ & $41,82 \%$ & $3.550,00$ & $37,71 \%$ \\
\hline
\end{tabular}

Fonte: Adaptado Blog Maxieduca (2019)

Indica: Que o Ativo Circulante no ano de 2019 representava 54,66\% dos Ativos daquele ano.

Conforme o Blog Maxieduca (2019) o quadro acima representa que no BP, essa análise demonstra quanto cada conta representa em percentual no total do Ativo ou Passivo em questão; na DRE ela pode demonstrar o que mais está exigindo mais da receita em percentual, ou seja, quais as maiores despesas.

Aplicada ao departamento financeiro: demonstra quais as maiores despesas; podese, então, fazer o mapeamento para um projeto de redução de despesas para melhores resultados. 


\subsubsection{ANÁLISE HORIZONTAL}

Conforme Reis (2009) compara-se, em forma percentual, o valor de determinada verba ou determinado grupo de verbas em relação aos anos anteriores. Os valores obtidos por meio da análise horizontal são bem menos expressivos do que os obtidos pela análise vertical.

Fórmula para calcular a análise horizontal:

$$
\mathrm{AH}=\frac{\text { Valor atual do item }}{\text { Valor do item no periodo anterior }} \times 100
$$

Tabela 02 - Exemplo de Cálculo Análise Horizontal

\begin{tabular}{|l|l|l|l|}
\hline Exercício & $\begin{array}{l}\mathbf{3 1 . 1 2 . 2 0 1 9} \\
\mathbf{( R \$} \mathbf{~ m i l )}\end{array}$ & $\begin{array}{l}\mathbf{3 1 . 1 2 . 2 0 2 0} \\
\mathbf{( R \$} \mathbf{~ m i l )}\end{array}$ & $\begin{array}{l}\mathbf{3 1 . 1 2 . 2 0 2 1} \\
\mathbf{( R \$} \mathbf{~ m i l )}\end{array}$ \\
\hline $\begin{array}{l}\text { Receita } \\
\text { vendas }\end{array}$ & 8.105 & 9.894 & 12.310 \\
\hline Lucro Bruto & 2.510 & 2.990 & 3.980 \\
\hline
\end{tabular}

\begin{tabular}{|l|l|l|l|l|l|l|}
\hline Exercício & $\begin{array}{l}\mathbf{3 1 . 1 2 . 2 0 1 9} \\
\mathbf{( R \$} \text { mil) }\end{array}$ & $\begin{array}{l}\text { AH } \\
\text { (No } \\
\text { Índice) }\end{array}$ & $\begin{array}{l}\mathbf{3 1 . 1 2 . 2 0 2 0} \\
\mathbf{( R \$} \text { mil) }\end{array}$ & $\begin{array}{l}\text { AH } \\
\text { (No } \\
\text { Índice) }\end{array}$ & $\begin{array}{l}\mathbf{3 1 . 1 2 . 2 0 2 1} \\
\mathbf{( R \$ ~ m i l )}\end{array}$ & $\begin{array}{l}\text { AH } \\
\text { (No } \\
\text { Índice) }\end{array}$ \\
\hline $\begin{array}{l}\text { Rec. } \\
\text { Vendas }\end{array}$ & 8.105 & $100 \%$ & 9.894 & $122,07 \%$ & 12.310 & $151,88 \%$ \\
\hline $\begin{array}{l}\text { Lucro } \\
\text { Bruto }\end{array}$ & 2.510 & $100 \%$ & 2.990 & $119,12 \%$ & 3.980 & $158,57 \%$ \\
\hline
\end{tabular}

Fonte: Adaptado Blog Maxieduca (2019) 
Indica: a variação da conta ou do grupo em determinado período irá indicar a evolução das contas/grupos a serem analisados.

Conforme o Blog Maxieduca (2019) o quadro acima representa como ela nos demonstra a variação, temos, então, a evolução de cada item, demonstrando, assim, qual a tendência, por isso ela também é chamada de análise de tendências.

Aplicada ao departamento financeiro: Quando conseguimos visualizar qual a tendência de uma conta, principalmente na DRE, podemos nos programar para que o fluxo de caixa acompanhe esta linha, o que ajuda na administração dos recursos financeiros da empresa.

\subsubsection{INDICADORES DE LIQUIDEZ}

Padoveze (2014), em seu estudo, aponta que os indicadores de liquidez procuram evidenciar a condição da empresa de saldar suas dívidas. São indicadores extraídos apenas do Balanço Patrimonial, razão que explicita o porquê de serem considerados indicadores estatísticos.

\subsubsection{LIQUIDEZ IMEDIATA}

Martins; Diniz e Miranda (2012) nos explicam sobre o índice de liquidez imediata e ressaltam os aspectos sobre a parcela das dívidas de curto prazo (passivo circulante) que poderiam ser pagas imediatamente por meio dos valores relativos $\mathrm{e}$ equivalentes ao caixa disponível, representando, assim, o quanto que a organização tem em caixa para sanar as dívidas a serem vencidas a curto prazo. Conforme Assaf Neto (2012) afirma, a liquidez imediata demonstra quanto, em percentual do total da dívida, a empresa representa, bem como aponta, também, nessa análise em questão, a parcela que está classificada a curto prazo, ou seja, circulante, dívidas essas transformadas, portanto, em circunstâncias a serem liquidadas de imediato. Esse percentual geralmente é baixo, mas é pelo fato da pouca vontade das 
empresas em permanecerem com recursos monetários em caixa que é reduzida a rentabilidade.

Fórmula para calcular liquidez imediata:

\section{Liquidez Imediata $=\frac{\text { Disponivel }}{\text { Passivo Circulante }}$}

Tabela 03 - Exemplo de Cálculo Liquidez Imediata

Exercício 31.12.2019 (R\$ mil)

\begin{tabular}{|c|c|c|c|}
\hline Ativo & $45.900,00$ & Passivo & $45.900,00$ \\
\hline Ativo Circulante: & $17.900,00$ & Passivo Circulante: & $12.800,00$ \\
\hline Disponibilidades & $10.000,00$ & $\begin{array}{l}\text { Obrigações de Curto } \\
\text { Prazo. }\end{array}$ & $6.500,00$ \\
\hline Estoques & $2.000,00$ & Despesas Provisionadas & $6.300,00$ \\
\hline Contas a Receber & $3.700,00$ & Não Circulante & $4.900,00$ \\
\hline $\begin{array}{l}\text { Despesas } \\
\text { Antecipadamente }\end{array}$ & $2.200,00$ & Dívidas de longo Prazo & $4.900,00$ \\
\hline Não Circulante & $28.000,00$ & Patrimônio Líquido & $28.200,00$ \\
\hline Imobilizado & $10.000,00$ & Capital Social & $10.000,00$ \\
\hline Intangível & $8.000,00$ & Lucros Acumulados & $10.000,00$ \\
\hline \multirow[t]{2}{*}{ Investimentos } & $10.000,00$ & Reservas de Capital & $8.200,00$ \\
\hline & & Ações em Tesouraria & $-8.200,00$ \\
\hline
\end{tabular}

Fonte: Adaptado do Blog Apprendafixa.com.br (2020)

Indica: $A$ cada $R \$ 1,00$ disponível, ligado, também, à dívida a curto prazo.

Conforme o Blog Apprendafixa.com.br (2020) o quadro acima representa que, quanto maior, melhor. No caso do nosso exemplo equivale à $R \$ 0,78$. 
Aplicada ao departamento financeiro: Aqui o gestor financeiro pode identificar se o fluxo de caixa dele está preparado para o cumprimento de todos os seus compromissos a curto prazo, sendo que, no caso do nosso exemplo, não está, pois ele possui menos dinheiro do que precisa para quitar as despesas de curto prazo, então, neste caso, terá de vender mais o seu estoque para ter mais recursos.

\subsubsection{LIQUIDEZ GERAL}

Como afirmam Martins; Diniz e Miranda (2012), o índice de liquidez geral mostra o quanto a empresa possui de recursos de curto e longo prazo (ativo circulante + realizável a longo prazo) para cada real de dívidas de curto prazo(passivo circulante + passivo não circulante), ou seja, mostra a capacidade de pagamento atual da empresa em relação às dívidas ao longo prazo; considera tudo o que ela converterá em dinheiro (no curto e longo prazo); está relacionado com todas as dívidas assumidas (de curto e longo prazo).

Para Assaf Neto (2012), a liquidez geral é utilizada, também, como medida de segurança financeira da empresa a longo prazo, revelando sua capacidade de saldar todos seus compromissos.

Fórmula para calcular liquidez geral:

$$
\text { Liquidez Geral }=\frac{\text { Atwo Circulante }+ \text { Reallzatvel longo Prazo }}{\text { (Passivo Circulante }+ \text { Exiglvel Longo Prazo) }}
$$

Tabela 04 - Exemplo de Cálculo Liquidez Geral

\begin{tabular}{|l|l|}
\hline Exercício & $\mathbf{3 1 . 1 2 . 2 0 1 9} \mathbf{( R \$}$ mil) \\
\hline Ativo Circulante & $3.909,00$ \\
\hline Realizável a LP & 567,00 \\
\hline Permanente & $2.675,00$ \\
\hline
\end{tabular}

RC: 101796 


\begin{tabular}{|l|l|}
\hline $\begin{array}{l}\text { Ativo/Passivo Total } \\
\text { Passivo }\end{array}$ & $\mathbf{7 . 1 5 1 , 0 0}$ \\
\hline $\begin{array}{l}\text { Circulante } \\
\text { Exigível a LP }\end{array}$ & $1.980,00$ \\
\hline $\begin{array}{l}\text { Patrimônio } \\
\text { Líquido }\end{array}$ & 2781 \\
\hline
\end{tabular}

Fonte: Adaptado Blog Maxieduca (2019)

Indica: Quanto a empresa possui no seu ativo circulante e realizável a longo prazo para cada $R \$ 1,00$ de dívida total. Que no nosso exemplo corresponde a $R \$ 1,02$.

Aplicada ao departamento financeiro: É o cálculo de liquidez imediata do financeiro e pode identificar se tudo o que está assumindo como compromisso poderá ser pago mediante os recursos disponíveis e à atenção aos direitos, ou seja, o que ainda tem a receber e isso, mais uma vez, auxilia no fluxo de caixa da empresa.

\subsubsection{LIQUIDEZ CORRENTE}

De acordo com Padoveze (2009), esse índice é visto como o principal e o mais utilizado para analisar a capacidade de pagamento da empresa. Correlaciona todos os ativos realizáveis no curto prazo apontados nas demonstrações financeiras como ativos circulantes. Desse modo, a curto prazo, pagar-se-á os Passivos, classificados contabilmente como Passivos Circulantes. Conforme Martins, Diniz e Miranda (2012), o índice de liquidez corrente mostra o quanto a empresa possui de recursos de curto prazo (ativo circulante) para cada real de dívidas de curto prazo (passivo circulante). Portanto, se os índices de liquidez forem maiores que 1, significa que o capital circulante líquido $(\mathrm{CCL})$, nesse caso, atingirá um resultado positivo, pois será possível chegar a uma maior compatibilidade entre recursos que se espera pagar no curto prazo. Em outras palavras, o índice de liquidez corrente mostra a capacidade de pagamento da empresa a curto prazo. 
Fórmula para calcular liquidez corrente:

$$
\text { Liquidez Corrente }=\frac{\text { Ativo Circulante }}{\text { Passivo Circulante }}
$$

Tabela 05 - Exemplo de Cálculo Liquidez Corrente

\begin{tabular}{|c|c|}
\hline Exercício & 31.12.2019 (R\$ mil) \\
\hline Ativo Circulante & $3.900,00$ \\
\hline Realizável a LP & 567,00 \\
\hline Permanente & $2.675,00$ \\
\hline Ativo/Passivo Total & $7.151,00$ \\
\hline $\begin{array}{l}\text { Passivo } \\
\text { Circulante }\end{array}$ & $2.990,00$ \\
\hline Exigível a LP & $1.390,00$ \\
\hline $\begin{array}{l}\text { Patrimônio } \\
\text { Líquido }\end{array}$ & 2781 \\
\hline
\end{tabular}

Fonte: Adaptado Blog Maxieduca (2019)

Indica: Quanto a empresa possui no seu Ativo Circulante para cada $R \$ 1,00$ de seu Passivo Circulante, que, em nosso exemplo, é $\mathrm{R} \$ 1,30$.

Conforme o Blog Maxieduca (2019) o quadro acima representa que, quanto maior, melhor.

Aplicada ao departamento financeiro: assim como na liquidez imediata, o financeiro pode identificar tudo o que está se assumindo como compromisso, só que, nesse caso, a curto prazo, poderá ser pago, e, de acordo com o resultado, poderá executar uma programação a partir dos valores disponíveis. 


\subsubsection{LIQUIDEZ SECA}

Para Padoveze (2009), este índice assevera a possibilidade da organização em quitar as dívidas a curto prazo. O cálculo tem como base aqueles Ativos Circulantes subtraídos dos estoques e despesas do próximo exercício, de modo que, com a exclusão dos estoques, verifica-se se a entidade está dependente ou não das vendas no processo de liquidação de seus compromissos. Justificamos a exclusão das despesas do exercício seguinte do Ativo Circulante para calcular esse índice, porque quase sempre não são valores realizáveis em numerário.

Fórmula para calcular liquidez seca:

Liquidez Seca $=$

(Ativo Circulante - Estoque)

\section{Passivo Circulante}

Tabela 06 - Exemplo de Cálculo Liquidez Seca

\section{Exercício 31.12.2019 (R\$ mil)}

\begin{tabular}{|c|c|c|c|}
\hline Ativo & $38.900,00$ & Passivo & $38.900,00$ \\
\hline Ativo Circulante: & $10.900,00$ & Passivo Circulante: & $8.800,00$ \\
\hline Disponibilidades & $3.000,00$ & $\begin{array}{l}\text { Obrigações de Curto } \\
\text { Prazo. }\end{array}$ & $2.500,00$ \\
\hline Estoques & $2.000,00$ & Despesas Provisionadas & $6.300,00$ \\
\hline Contas a Receber & $3.700,00$ & Não Circulante & $1.900,00$ \\
\hline $\begin{array}{l}\text { Despesas } \\
\text { Antecipadamente }\end{array}$ & $2.200,00$ & Dívidas de longo Prazo & $1.900,00$ \\
\hline Não Circulante & $28.000,00$ & Patrimônio Líquido & $28.200,00$ \\
\hline Imobilizado & $10.000,00$ & Capital Social & $10.000,00$ \\
\hline Intangível & $8.000,00$ & Lucros Acumulados & $10.000,00$ \\
\hline
\end{tabular}

RC: 101796

Disponível em:

https://www.nucleodoconhecimento.com.br/contabilidade/demonstracao-do-resultado 
Fonte: Adaptado Blog Aprendafixa.com.br (2020)

Indica: Quando a empresa possui em seu ativo líquido para cada $R \$ 1,00$ de seu Passivo Circulante. No caso do nosso exemplo, equivale à $R \$ 1,01$.

Aplicada ao departamento financeiro: Com esse índice, o departamento financeiro acaba contando com o que tem a receber para que possa quitar suas contas de curto prazo, o que pode até virar meta de recebimento ou recuperação de inadimplência. Pode apontar, também, para mais vendas, já que, como demonstra o nosso exemplo, o resultado pode ser bem apertado.

\subsubsection{ANÁLISE DO ENDIVIDAMENTO E ESTRUTURA}

Martins; Diniz e Miranda (2012), ao analisarem a solvência de uma empresa, ressaltam que é essencial o conhecimento quanto aos prazos relacionados aos vencimentos das dívidas. O índice direcionado à composição do endividamento, então, aponta a quantidade da dívida total exigida a curto prazo. O resultado é a soma do Passivo Circulante com o Passivo Não Circulante com terceiros. Do ponto de vista financeiro, é comum que a empresa busque recursos de longo prazo para financiamento do Ativo Não Circulante e recursos de curto prazo para financiamento do Ativo Circulante. Embora não existam regras fixas, pois cada entidade possui uma estrutura de capitais que otimizam seus resultados, uma empresa com níveis mais elevados de endividamento no longo prazo terá melhores condições de gerar recursos para fazer frente a compromissos numa determinada crise, por exemplo.

\subsubsection{ANÁLISE DE RENTABILIDADE E LUCRATIVIDADE}

Para Assaf Neto e Silva (2012), a atividade bancária comporta-se similarmente ao demais tipos de negócios, diferenciando-se, basicamente, pela natureza dos fatores colocados à disposição Numa instituição financeira, os recursos captados 
representam suas matérias primas, que são negociadas principalmente sob a forma de créditos e empréstimos concedidos e investimentos. Os principais índices de análise de rentabilidade adaptados à atividade bancária podem ser classificados em três grupos:

Índice básicos de rentabilidade são baseados em 3 medidas financeiras:

1. Retorno sobre o patrimônio líquido: fornece ganho percentual auferido pelos proprietários como uma consequência das margens de lucro, da eficiência operacional, do planejamento eficiente dos seus negócios;

2. Retorno sobre o investimento total: aponta as oportunidades suscitadas das negociações feitas junto ao banco e, desse modo, mensura-se a influência a partir da qualidade do lucro gerado pelos Ativos e Juros Passivos. Indica o retorno apurado sobre o capital (ativo)total investido;

3. A margem líquida ampara-se nos resultados múltiplos oriundos da administração dos Ativos e Passivos dos bancos. Contempla-se as taxas, prazos, receitas e, ainda, as despesas, o que permite a correta avaliação da função de intermediação financeira mediada pelo banco.

\subsubsection{ANÁLISE DAS ATIVIDADES OPERACIONAIS}

Martins; Diniz e Miranda (2012) apontam que o ciclo operacional demonstra o período do processo produtivo. Corresponde à etapa que compreende desde a compra da mercadoria ou matéria-prima até o recebimento do caixa, que é resultado da venda do produto. Tem como objetivo proporcionar uma visão de tempo gasto pela entidade em cada fase do processo produtivo, bem como apontar o volume de capital necessário para suportar financeiramente o prazo envolvido entre a aquisição da mercadoria e o recebimento da venda. 


\subsection{DIAGNÓSTICO DA ANÁLISE DO BALANÇO PATRIMONIAL E DEMONSTRAÇÃO DO RESULTADO DO EXERCÍCIO}

Conforme Assaf Neto (2009) aponta, o profissional deve nortear-se por uma metodologia que permite o raciocínio científico, já que o diagnóstico dessa análise deve espelhar a real situação da empresa. E este é o último passo da análise das Demonstrações Contábeis. Então, nesse momento, geralmente, segue-se este modelo que Assaf Neto disponibiliza:

Figura 01 - Diagnóstico da Análise

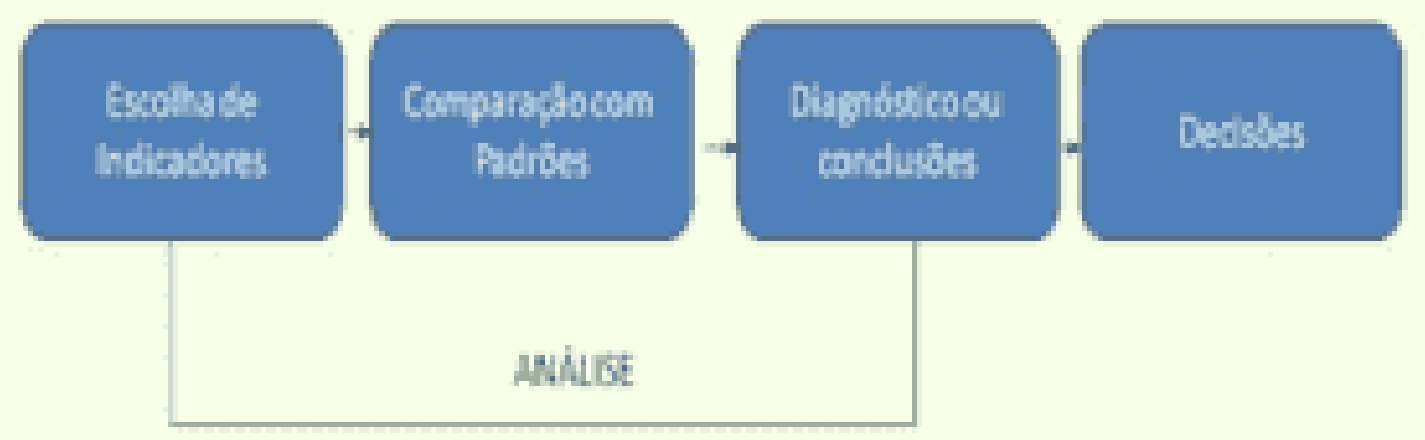

Fonte: Assaf Neto (2009)

Conforme Assaf Neto (2009) discorre com base no quadro, afirma-se que, para que a pessoa possa analisar as demonstrações, deve se perguntar se a situação financeira e econômica da empresa está bem ou não, bem como deve se questionar quanto aos pontos fortes e fracos financeiros e econômicos. Pode investigar, também, se há possibilidade de solvência da empresa. Com a resposta para essas perguntas, a pessoa que avalia as demonstrações pode auxiliar na tomada de decisões, indagando se é viável investir ou não na empresa, assim como se ela tem competência de solvência; pode, também, nos dizer qual o risco de conceder crédito à empresa, destacando os pontos fortes e fracos que ela possui e, mas não menos importante, deve comparar sua atuação com seus concorrentes. 


\subsection{ADMINISTRAÇÃO FINANCEIRA}

Hoji (2014) explica que a administração financeira busca analisar, planejar e visa alcançar o controle financeiro, assim como viabilizar para seus profissionais mecanismos que permitem mais bem tomadas de decisões quanto ao investimento e financiamento, focando no maior objetivo da empresa, que é maximizar o seu valor de mercado. Diz, também, que o administrador financeiro precisa, continuamente, do apoio de profissionais técnicos especializados de outros departamentos, tais como controller, contador, tesoureiro e gerente financeiro. Todos são fundamentais. Portanto, uma boa administração financeira é crucial para que a empresa se mantenha bem no mercado, necessitando, então, de um bom planejamento, e, para isso, deve contar com profissionais capacitados da área, sendo que estes devem sempre aprimorar os seus conhecimentos e conceitos.

\subsubsection{PLANEJAMENTO FINANCEIRO}

Hoji (2014) ressalta, em seu estudo, que o planejamento financeiro se divide em três níveis, que são: Planejamento estratégico, que é um planejamento de longo prazo e, por isso, fica sobre a responsabilidade e ótica dos diretores e presidentes da empresa. O planejamento tático, por sua vez, busca alavancar os resultados por meio de ações a curto prazo, analisando, assim, de maneira contínua, todas as alternativas dentro do mercado. Há, por fim, o planejamento operacional. Este trabalha obedecendo o planejamento estratégico, focado em maximizar os recursos das empresas aplicados no dia a dia.

\subsubsection{FUNÇÃO DO DEPARTAMENTO FINANCEIRO}

Conforme Hoji (2014) nos explica, a função do departamento financeiro é colocar em prática o planejamento de seu gestor, controlar os seus recursos financeiros e nortear quanto a melhor maneira de conduzir as atividades operacionais de curto e longo prazo, para garantir que os recursos sejam aplicados da melhor forma que a empresa obtenha um melhor resultado, já que todas as atividades operacionais 
demandam recursos. Nesse sentido, entende-se que o departamento financeiro deve se ater às melhores estratégias voltadas ao gerenciamento dos recursos financeiros da entidade. Assim sendo, tudo aquilo relacionado às finanças, é uma preocupação deste setor. A função principal é a garantia da boa administração do patrimônio, pois, dessa forma, a empresa maximiza seus lucros e reduz seus gastos.

\subsubsection{CONTROLE DE CAPITAL DE GIRO}

Sanvicente (2009) explica que o capital de giro representa todos os ativos correntes e ativos circulantes, quando a empresa já em atividade tem disponível seu ativo de alta liquidez, ou seja, bens e direitos que podem ser convertidos rapidamente em dinheiro, o que permite que esta liquide suas obrigações de curto prazo como: fornecedores, impostos, salários de funcionários etc. Então, o capital de giro da empresa representa todos os recursos financeiros necessários para continuar operando regularmente. No início da vida da empresa, o cálculo do capital de giro é realizado para analisar quanto será imprescindível manter em caixa para conseguir desempenhar todas as obrigações diárias de acordo com os planos efetuados para o negócio.

O capital de giro, portanto, é o dinheiro fundamental para a continuidade da empresa, isto é, o capital do qual precisa para manter operando continuamente. É parte do investimento que fica reservado para pagamento de despesas e custos ao longo prazo e incorpora todos os valores em caixa, assim como os depósitos em contas bancárias e valores a receber para quitar as despesas empresariais.

[...] o capital de giro constitui-se no fundamento básico da avaliação do equilíbrio financeiro de uma empresa. Pela análise de seus elementos patrimoniais são identificados os prazos operacionais. $O$ volume de recursos permanentes (longo prazo) que se encontra financiando o giro e as necessidades de investimento operacional (PADOVEZE, 2014, p. 247).

Conforme Assaf Neto e Silva (2012), o capital de giro representa os recursos utilizados pela empresa para financiar as necessidades operacionais observadas desde a aquisição da matéria-prima ou mercadorias até apuração das vendas do 
produto, sendo, então, parte essencial para o bom desempenho da empresa, considerando as condições de mercado e utilizando estratégias que revelam a atuação sobre o montante de capital de giro. Deve-se observar a viabilidade financeira de seus negócios. Para Padoveze (2014), a nomenclatura capital de giro advém de uma visão circular.

O Ativo circulante, comumente chamado de capital de giro, representa a porção do investimento que circula, de uma forma para outra, na condução normal dos negócios. Esse conceito abrange a transição recorrente de caixa para estoques, destes para os recebíveis e de volta para o caixa. Na qualidade de equivalentes de caixa, os títulos negociáveis também são considerados parte do capital de giro (GITMAN; ZUTTER, 2017, p. 547).

Nesse contexto, pode-se discutir sobre as próximas variáveis.

\subsubsection{CONTAS A PAGAR}

Sanvicente (2009) também afirma que uma boa administração voltada à disponibilidade preserva a maior liquidez possível sem provocar prejuízos por manutenção de saldos excessivos, de forma que todas as obrigações financeiras assumidas por uma empresa, ou seja, as suas contas a pagar, qualquer tipo de pagamento, perpassa por essa questão. Os seus colaboradores, contas de consumo ou compra de matéria-prima também são aspectos que integram o eixo das contas a serem pagas. $O$ assistente de contas a pagar e receber é o responsável por organizar e planejar todos os documentos comprobatórios de entrada e saída de recursos da empresa. É uma tarefa que requer atenção e organização, já que é necessário classificar cada uma das contas e programar os pagamentos e recebimentos de forma eficaz.

\subsubsection{CONTAS A RECEBER}

Sanvicente (2009) informa que o eixo de contas a receber corresponde aos valores que a empresa tem a receber de seus clientes, e que o objetivo é obtenção da maior liquidez possível, sem provocar a inatividade de recursos excessivos. O setor de 
contas a receber é o responsável pelo controle do eixo "contas do cliente a serem pagas", isto é, representa o ativo da entidade. A sua importância na entidade, portanto, como está ligada à organização, possibilita a obtenção de informações benéficas para os gestores financeiros, como conhecer clientes que pagam em dia. Faz parte do setor o envio de cartas de cobrança para clientes inadimplentes, assim como inserção ao SPC e protesto de títulos.

\subsubsection{CONTROLE DO FLUXO DE CAIXA}

Para Sanvicente (2009), Fluxo de Caixa é um instrumento de gestão financeira que provisiona para períodos futuros todas as entradas e as saídas de recursos financeiros da empresa, demonstrando como será o saldo de caixa para o período estimado. Logo, o controle de caixa registra as movimentações financeiras da empresa, demonstrando o saldo atual. O fluxo de caixa, ainda que também faça esse registro, permite calcular as entradas e saídas de dinheiro que ocorrerão em um período futuro, assessorando o planejamento do gestor.

\section{MATERIAIS E MÉTODOS}

Para Libório e Terra (2015), materiais e métodos representam o conjunto de regras básicas aplicadas a uma investigação científica. Detalham tudo o que será realizado na pesquisa de forma parcial e confiável. Os materiais são os que serão utilizados para aplicação dessas regras. Devem possuir tal nível de detalhamento que, se o projeto for entregue para outra pessoa, ela deve conseguir executar a pesquisa exatamente da mesma forma que você executaria.

\subsection{PROCEDIMENTOS METODOLÓGICOS}

Para Gil (2008) os procedimentos metodológicos são os que fornecem norte à execução da pesquisa. Essa organização pode mudar conforme as particularidades da pesquisa. Este projeto realizou-se por meio de pesquisas bibliográficas e levantamento de dados, com o objetivo de identificar, a partir de livros, artigos e 
dissertações sobre o tema escolhido, os dados relevantes sobre o cenário, com finalidade de entender e analisar as demonstrações contábeis, pois essas podem ajudar o departamento financeiro.

\subsubsection{QUANTO À NATUREZA}

Quanto à natureza, Kinchescki; Alves e Fernandes (2015) relatam que pode ser básica, pois tem como objetivo acender conhecimentos novos, porém, sem a aplicação prática. Discorre-se sobre interesses universais que envolvem verdades Pereira et al. (2018) explicam que a pesquisa aplicada promove o conhecimento necessário à solução de problemas específicos, com aplicação prática. Escolhemos a pesquisa básica pois o nosso tema pôde ser mais bem explicado e exemplificado, tomando como base livros de autores que nos demonstram como solucionar nossa questão problema. É uma maneira já praticada no mercado há muitos anos e atualizada para os dias atuais. A ferramenta apresentada neste estudo deve ser adaptada para cada realidade. A pesquisa apresentou, portanto, uma visão ampla a partir da análise.

\subsubsection{QUANTO AOS FINS}

Menezes et al. (2019) demonstram, a partir do ponto de vista da pesquisa qualitativa, que, quanto aos objetivos, a pesquisa pode assumir algumas formas, sendo elas a exploratória, descritiva e explicativa. Menezes et al. (2019) também relatam que, por meio do controle de variáveis, a pesquisa explicativa busca analisar a realidade de forma profunda, bem como tem como objetivo fundamental, ao longo do estudo, identificar qual a variável livre ou aquela que causa a variável, a depender do que está ocorrendo, para estudá-la, em seguida. Escolhemos a pesquisa explicativa pois ela nos ajudou alcançar os objetivos deste este artigo com nitidez, pois exploramos as principais técnicas de análise que permitiram, por sua vez, identificar as variáveis a serem operacionalizadas no trabalho, orientando, assim, o departamento financeiro nas tomadas de decisões. 


\subsubsection{QUANTO AOS MEIOS}

Conforme Gil (2008), as pesquisas bibliográficas são desenvolvidas com apoio em materiais já preparados, compostos, principalmente, por livros e artigos científicos. Segundo Gil (2008), os livros são fontes bibliográficas necessárias. A depender de como forem utilizados, podem ser classificados como livros de leitura corriqueira ou de referência. Utilizamos os meios bibliográficos de pesquisa, pois eles apresentaram os conceitos básicos que foram necessários à introdução ao assunto, assim como ao desenvolvimento do tema, tendo, como base, os livros referências nas áreas financeira e contábil.

\section{CONSIDERAÇÕES FINAIS}

Desenvolvemos esta pesquisa no intuito de buscarmos melhor resultados para as empresas e demonstrarmos que podemos alcançá-los de maneira simples, porém, de forma que demanda preparo profissional, principalmente do analista que tem função de interpretar o balanço patrimonial e as demonstrações de resultado do exercício da empresa que atua. Nosso objetivo geral foi o de destacar a importância da análise financeira e econômica de Balanço Patrimonial e da Demonstração do Resultado do Exercício para fornecermos maior suporte às decisões do departamento financeiro. Demonstramos como ele pode ser alcançado a partir de diferentes técnicas expostas no artigo, tais como: Análise Vertical; Análise Horizontal; Análise pelo Modelo Dinâmico de Fleuriet; Indicadores de Liquidez, como Liquidez Imediata, Liquidez Geral, Liquidez Corrente e Liquidez Seca; Análise do Endividamento e Estrutura; Análise de Rentabilidade e Lucratividade; e Análise das Atividades Operacionais, na qual todas essas análises podem fornecer informações na tomada de decisão.

A pergunta de pesquisa foi: Como a análise financeira e econômica de Balanço Patrimonial e da Demonstração do Resultado do Exercício pode contribuir para a tomada de melhores decisões e melhor desempenho no departamento financeiro? Neste artigo, identificamos que, por meio da análise financeira das demonstrações 
contábeis, é possível evidenciar e confrontar informações e elementos de uma organização, mostrando os aspectos relativos à realidade econômica, financeira e patrimonial da empresa, partindo-se de estudos mais aprofundados. Considerou-se as técnicas básicas da área sendo aplicadas por um analista bem-preparado profissionalmente. Com este artigo, conseguimos afirmar que uma análise de qualidade auxilia na tomada de decisões que envolvem aplicações financeiras, investimentos, índices de capitais, liquidez e previsões. As ações da empresa adotaram, então, um padrão estratégico que fomentou maior lucro e segurança para que a entidade pudesse administrar seu patrimônio, de forma que alcançamos, então, nossos objetivos específicos.

Pretendeu-se: aprimorar as decisões do departamento financeiro; demonstrar como a análise financeira e econômica de Balanço Patrimonial e a Demonstração do Resultado do Exercício podem contribuir para o melhor planejamento do departamento financeiro; e explicar como o departamento financeiro pode influenciar positivamente os resultados da contabilidade por meio de uma boa organização.

Portanto, essas técnicas são indispensáveis para uma empresa que busca o seu lugar no mercado, pois apenas com elas poderá se desenvolver de maneira sólida e estruturada, uma vez que, por estar preparada, poderá aguentar, se for o caso, crises financeiras e econômicas que seu mercado poderá passar. Sendo assim, nós, profissionais da contabilidade, devemos ser os primeiros a alertar nossos clientes e chefes para que sigam este caminho, que é o que leva qualquer entidade, no mercado atual, altamente competitivo, ao sucesso, portanto, precisamos estar preparados para isto.

\section{REFERÊNCIAS}

ASSAF NETO, A. Estrutura e análise de Balanços: um enfoque econômicofinanceiro. 10ª ed. São Paulo: Atlas, 2012.

ASSAF NETO, A. Finanças Corporativas e Valor. 4를 ed. São Paulo: Atlas, 2009. 
ASSAF NETO, A.; SILVA, C. A. T. Administração do capital de giro. $4^{\underline{a}}$ ed. São Paulo: Atlas, 2012.

GIL, A. C. Métodos e técnicas de pesquisa social. 6ª ed. São Paulo: Atlas, 2008.

GITMAN, L. J.; ZUTTER, C. J. Princípios de administração financeira. 14ª ed. São Paulo: Pearson, 2017.

HOJI, M. Administração financeira e orçamentária: matemática financeira aplicada, estratégias financeiras, orçamento empresarial. 9ª ed. São Paulo: Atlas, 2010.

KINCHESCKI, G. F.; ALVES, R.; FERNANDES T. R. T. Tipos de metodologias adotadas nas dissertações do programa de pós- graduação em administração universitária da Universidade Federal de Santa Catarina, no período de 2012 a 2014. In: XV Colóquio Internacional de Gestão Universitária, 2015.

LIBÓRIO, D.; TERRA, L. Metodologia científica. São Paulo: Rede Internacional de Universidades Loureate, 2015.

MARTINS, E.; DINIZ, J. A; MIRANDA, G. J. Análise avançada das demonstrações contábeis. $3^{\mathrm{a}}$ ed. São Paulo: Atlas, 2012.

MENEZES, A. H. N. et al. Metodologia científica, teoria e aplicação na educação à distância. Petrolina - PE: Universidade Federal do Vale do São Francisco, 2019.

PADOVEZE, C. L. Contabilidade Gerencial: um enfoque em sistemas de informação contábil. 6. ${ }^{a}$ ed. São Paulo: Atlas, 2009.

PADOVEZE, Clóvis Luís. Práticas Contábeis Internacionais (IFRS) versus orçamento como informações preditivas. Revista de Finanças e Contabilidade da Unimep, v. 1, n. 1, p. 23-32, 2014. 
PEREIRA, A. S. et al. Metodologia da pesquisa científica. Santa Maria: Universidade Federal de Santa Maria, UAB/NTE/UFSM, 2018.

REIS, A. C. de. R. Demonstrações Contábeis: estrutura a análise. $3^{a}$ ed. São Paulo: Editora Saraiva, 2009.

SANVICENTE, A. Z. Administração financeira. $3^{\underline{a}}$ ed. 17. reimp. São Paulo: Atlas, 2009.

Enviado: Outubro, 2021.

Aprovado: Novembro, 2021. 